GRADIATION\&APPLICATIONS

ISSN 2466-4294 (online) | rad-journal.org

Vol. 3 | Issue 3 | pp. 202-208, 2018

doi: 10.21175/RadJ.2018.03.034

Original research paper

\title{
COMPARATIVE ANALYSIS OF HYPERSPECTRAL VEGETATION INDICES FOR REMOTE ESTIMATION OF LEAF CHLOROPHYLL CONTENT AND PLANT STATUS*
}

\author{
Kalinka Velichkova1, Dora Krezhova ${ }^{* *}$ \\ ${ }^{1}$ University of Mining and Geology "St. Ivan Rilski”, Sofia \\ ${ }^{2}$ Space Research and Technology Institute, Bulgarian Academy of Sciences
}

\begin{abstract}
Leaf chlorophyll (Chl) content, at the leaf and canopy level, is an important biochemical parameter because of its crucial role in photosynthesis and in plant functioning. Furthermore, it provides an indication of the plant nutritional state and stress. Due to the reliable, rapid, and non-destructive advantages, hyperspectral remote sensing plays a significant role in monitoring and assessing the plant biophysical variables. In this study, a set of Chlrelated vegetation indices (VIs) derived from the leaf reflectance data of young pepper plants infected by Cucumber Mosaic Virus (CMV) were tested for estimating the changes in the Chl content and plant status. Hyperspectral reflectance data were collected by means of a portable fiber-optics spectrometer in the spectral range of 350-1100 $\mathrm{nm}$. The effect of two growth regulators, MEIA (beta-monomethyl ester of itaconic acid) and BTH (benzo(1,2,3)thiadiazole-7-carbothioic acid-S-methyl ester), on the Chl content and respectively on the development of the viral infection was investigated too. Four categories VIs: normalized difference (ND) VIs; simple ratio (SR) VIs; single-band reflectance or simple difference (SD) VIs, and some other forms of VIs, were tested using statistical analyses (ANOVA and Tukey-Kramer's tests) to explore their potentials in the Chl content estimation. To enhance the sensitivity of the VIs, modified VIs were tested in some other combinations of narrow bands. The statistical analyses showed that the Modified Red Edge Simple Ratio (MRESR) index, Vogelmann Red Edge index (VREI1), and Pigment index (PI) were most sensitive to the Chl content changes. The Normalized Difference VI (NDVI) and Triangular Vegetation Index (TVI) turned out to be insensitive to Chl variations. The rest of the VIs were responsible for Chl variations but with less sensitivity.
\end{abstract}

Key words: Biophysical variables, chlorophyll, hyperspectral reflectance, stress, vegetation indices, viral infection

\section{INTRODUCTION}

Leaf Chl content is a good indicator of photosynthesis activity, stress and nutritional state of plants. It is very important for assessment of crop health and prediction of crop yield [1]. The photosynthetic apparatus is a sensitive indicator of plant state due to the rapid changes in Chl content induced by the variations of the environmental conditions. Chl content can also be used to indirectly estimate soil nitrogen content or to define optimum fertilization. Therefore, much attention has recently been paid to the development of practical methods for an accurate $\mathrm{Chl}$ estimation using remote sensing (RS) techniques.

The RS technique based on leaf reflectance measurements in the visible (VIS) and near-infrared (NIR) spectral ranges has been shown to be useful for estimating plant chemistry and physiology from an individual plant to a canopy. Compared to conventional analytical methods, it is a rapid, reliable and nondestructive method, requiring less sample preparation, with less or no chemical reagents [2]. This method is highly adaptable to automated and in situ measurements and has the potential to analyze various plant properties simultaneously.

The advances in RS technologies (optical sensors with high spectral and spatial resolutions) allow receiving accurate information for most important biophysical variables. Many algorithms have been developed for a remote estimation of biophysical characteristics of vegetation, such as combinations of spectral bands, derivatives of reflectance spectra, neural networks, inversion of radiative transfer models, and several statistical approaches [3, 4]. Quite simple and effective algorithms for quantitative and qualitative evaluations of vegetation biophysical variables are based on the mathematical combinations of VIS and NIR reflectance bands, in the form of spectral vegetation indices (VIs). Such algorithms improve the sensitivity to the investigated vegetation parameters by minimizing the influence of extraneous factors affecting leaf and canopy reflectance and reduce the abundance of data sets [5].

\footnotetext{
* This paper was presented at the Sixth International Conference on Radiation and Applications in Various Fields of Research (RAD 2018), Ohrid, Macedonia, 2018.

** dora.krezhova@gmail.com
} 
K. Velichkova, D. Krezhova, Hyperspectral vegetation indices..., Rad. Applic., 2018, 3, 3, 202-208

Developments in hyperspectral RS have provided new VIs or indicators of plant biochemical and biophysical properties. Most of the studies involving the novel spectral VIs have been conducted at the leaf or canopy level and often are focused on mitigating unwanted reflectance effects, while increasing the indices' sensitivity to the investigated parameters [6, 7].

VIs introduced for the assessment of Chl content are initially developed at the leaf level because an assessment of the sensitivity of such a method at the leaf level is regarded as the first step for further research at the canopy scale and for the remote estimation of Chl content from satellite observation. Chl-related VIs are widely proposed for assessing various characteristics of vegetation as well as yielding prognosis [8]. Some ecological stresses can also be detected $[9,10]$. The investigations are focused on evaluating the reflectance in individual narrow bands, two or more band ratios and combinations, slopes or other formulations.

The total Chl content in leaves decreases in stress vegetation, changing the proportion of light-absorbing pigments and leading to a lower overall absorption due to lower $\mathrm{Chl} a$ and $\mathrm{Chl} b$ concentrations at the leaf level. The graphs in Fig. 1 show the absorption spectra for the main leaf pigments - Chl $a$, Chl $b$, and carotenoids. Each type of pigment can be identified by the specific pattern of wavelengths it absorbs from VIs light. Chl $a$ and $\mathrm{b}$ absorb radiation at the red and blue bands. Carotenoids absorb in the short-wavelength blue region, and reflect the longer yellow, red, and orange wavelengths. Recent studies show that the total carotenoid to $\mathrm{Chl}$ ratio increases during vegetation stress or senescence, as the declines in Chl content exceed any corresponding declines in carotenoid content [9].

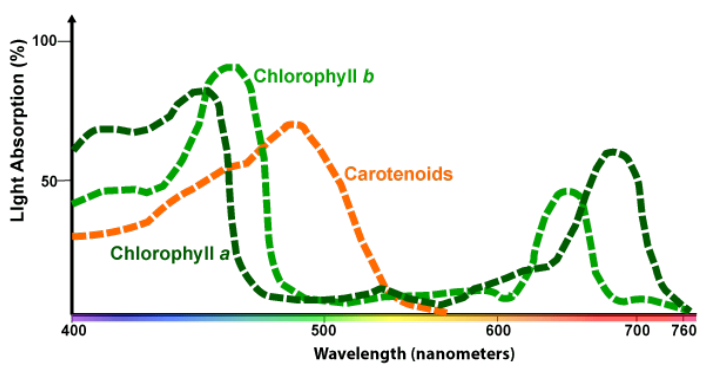

Figure 1. Absorption spectra for Chlorophyll a, Chlorophyll b, and Carotenoids

Significant differences in the reflectance spectra between healthy and stressed vegetation due to changes in pigment content have been detected in the reflectance green peak and along the red edge. Several studies have found that the wavelengths adjoining the $\mathrm{Chl}$ maximum absorption bands $(700 \mathrm{~nm})$ and the green $(550 \mathrm{~nm})$ bands are the most sensitive to changes in the wide range of Chl contents [11].

The objective of this study is to evaluate the sensitivity of a set of VIs for estimating the changes in the Chl content and physiological state of young pepper plants infected by Cucumber Mosaic Virus (CMV). The effect of two growth regulators: MEIA (beta-

203 monomethyl ester of itaconic acid) and BTH (benzo(1,2,3)thiadiazole-7-carbothioic acid-S-methyl ester) on the Chl content and respectively on the development of a viral infection in the plants was investigated too.

\section{MATERIALS AND METHODS}

\subsection{Plant material}

Pepper plants cultivar Sivria, sensitive to CMV, were grown in a greenhouse under controlled conditions. Four groups of plants were used for the investigations. The first group included healthy (control) plants. At growth stage 4-6 expanded leaf the plants of the second group were inoculated with CMV. The plants of the other two groups were treated with growth regulators: MEIA (beta-monomethyl ester of itaconic acid) and BTH (benzo(1,2,3)thiadiazole-7carbothioic acid-S-methyl ester). On the next day, the plants were inoculated with CMV [12].

\subsection{Leaf reflectance measurements}

Spectrometric measurements of the reflected radiation from fresh detached leaves were carried out in laboratory conditions, one and two weeks after the inoculation. Hyperspectral reflectance data were collected by means of a portable fiber-optics spectrometer USB200o (Ocean Optics) in the spectral range of $350-1100 \mathrm{~nm}$ at a spectral resolution of 1.5 $\mathrm{nm}$. The spectrometer was placed $30 \mathrm{~cm}$ vertically above the leaf sample and the field of view was $6 \mathrm{~cm}$ in diameter. A halogen lamp was used as a light source in order to minimize a potential spectral variation between samples due to the illumination condition. Leaf reflectance spectra were recorded against barium sulphate plate as a standard, whereas black velvet was used as the background. The spectral reflectance characteristics (SRC) of the plants were determined as the ratio between the radiation reflected from the leaves and the one reflected from the standard.

\subsection{Vegetation indices used in analyses}

In this study, hyperspectral leaf reflectance data at different narrow bands in green, blue, red, and NIR spectral regions were used to evaluate a set of selected Chl-related VIs. The type, equations and sources of indices are given in Table 1 . Only reflectance spectra in the VIs and NIR spectral range (450-850 $\mathrm{nm}$ ) were considered in the spectral analyses because data in this part of electromagnetic spectrum are informative for leaf pigment variations.

Narrowband VIs were classified into four categories: normalized difference (ND) VIs, singleband (SB) or single-difference (SD) VIs, simple-ratio (SR) VIs, and other forms of indices. Two-band indices were evaluated using a custom developed computer programme to traverse several band combinations of the SD, SR and ND indices. These VIs were calculated using two wavebands $\left(\lambda_{1}\right.$ and $\left.\lambda_{2}\right)$ to select the most effective two-band combinations for the assessment of Chl content, as shown in Eqs. (1)-(3): 
K. Velichkova, D. Krezhova, Hyperspectral vegetation indices..., Rad. Applic., 2018, 3, 3, 202-208

$$
\begin{aligned}
& S R\left(R_{\lambda 1}, R_{\lambda 2}\right)=\frac{R_{\lambda 1}}{R_{\lambda 2}}, \\
& S D\left(R_{\lambda 1}, R_{\lambda 2}\right)=R_{\lambda 1}-R_{\lambda 2}, \\
& N D\left(R_{\lambda 1}, R_{\lambda 2}\right)=\frac{\left|R_{\lambda 1}-R_{\lambda 2}\right|}{R_{\lambda 1}+R_{\lambda 2}} .
\end{aligned}
$$

The Normalized Difference VI (NDVI) [13] is the most commonly used multi-spectral index. At the leaf level, the NDVI is correlated with leaf Chl content; however, at the canopy scale, the NDVI is much more affected by the changes in the leaf area index (LAI) [14]. Its calculation is based on the difference in reflectance at the red (660-680 $\mathrm{nm})$ and NIR (750-850 nm) spectral bands. Table 1 contains the VIs selected based on the original NDVI equation, which are: modified NDVI (mNDVI), modified DATT index (MDATT), Photochemical Reflectance index (PRI), and

\begin{tabular}{|c|c|c|}
\hline $\begin{array}{l}\text { Type } \\
\text { of VI }\end{array}$ & Equation & Source \\
\hline ND & & \\
\hline NDVI & $\left(\mathrm{R}_{845}-\mathrm{R}_{665}\right) /\left(\mathrm{R}_{845}+\mathrm{R}_{665}\right)$ & [13] \\
\hline mNDVI & $\left(\mathrm{R}_{750}-\mathrm{R}_{705}\right) /\left(\mathrm{R}_{750}+\mathrm{R}_{705}\right)$ & [15] \\
\hline MDATT & $\left(R_{719}-R_{726}\right) /\left(R_{719}-R_{743}\right)$ & {$[8]$} \\
\hline PRI & $\left(R_{531}-R_{570}\right) /\left(R_{531}+R_{570}\right)$ & [17] \\
\hline MRESR & $\left(\mathrm{R}_{750}-\mathrm{R}_{450}\right) /\left(\mathrm{R}_{705}-\mathrm{R}_{450}\right)$ & {$[27]$} \\
\hline SR & & \\
\hline NR1 & $\mathrm{R}_{760} / \mathrm{R}_{695}$ & [10] \\
\hline NR2 & $\mathrm{R}_{800} / \mathrm{R}_{650}$ & [19] \\
\hline $\mathbf{Z M}$ & $\mathrm{R}_{750} / \mathrm{R}_{710}$ & [9] \\
\hline $\mathbf{G}$ & $\mathrm{R}_{554} / \mathrm{R}_{667}$ & [20] \\
\hline BG & $\mathrm{R}_{677} / \mathrm{R}_{554}$ & {$[21]$} \\
\hline VREI1 & $\mathrm{R}_{740} / \mathrm{R}_{720}$ & [22] \\
\hline or SD & $1 / R_{700}$ & [23] \\
\hline & $1 / R_{550}-1 / R_{750}$ & [23] \\
\hline Chlgreen & $\mathrm{R}_{760} / \mathrm{R}_{55 \mathrm{o}}-1$ & [21] \\
\hline Chl red edge & $\mathrm{R}_{760} / \mathrm{R}_{714}-1$ & {$[21]$} \\
\hline $\begin{array}{l}\text { Others } \\
\text { CARI }\end{array}$ & $\left(R_{700}-R_{670}\right)-0.2\left(R_{700}+R_{550}\right)$ & {$[24]$} \\
\hline MCARI & $\begin{array}{l}{\left[\left(\mathrm{R}_{700}-\mathrm{R}_{670}\right)-\right.} \\
\left.\mathrm{o.2}\left(\mathrm{R}_{700}+\mathrm{R}_{550}\right)\right] \mathrm{R}_{700} / \mathrm{R}_{670}\end{array}$ & [25] \\
\hline NGPI & $1-\left(\lambda_{r}-\lambda_{b}\right)\left(R_{r}+R_{b}\right) /\left(2 \int_{\lambda_{b}}^{\lambda_{r}} R_{\lambda} \mathrm{d} \lambda\right)$ & $\begin{array}{l}\text { in this } \\
\text { study }\end{array}$ \\
\hline TVI & $\begin{array}{l}0.5\left[120\left(R_{750}-R_{550}\right)-\right. \\
\left.200\left(R_{670}-R_{550}\right)\right]\end{array}$ & {$[26]$} \\
\hline
\end{tabular}
Modified Red Edge Simple Ratio (MRESR) index.

Table 1. Chlorophyll vegetation indices used in this study

ND - normalized difference, SR - simple ratio, SB - single band, SD - simple difference, $\mathrm{R}$ - leaf reflectance

The modified NDVI with wavelengths of $705 \mathrm{~nm}$ and $750 \mathrm{~nm}$ [15] was developed to eliminate the effects of surface reflectance by incorporating the blue band. It is more strongly correlated with the total $\mathrm{Chl}$ content. The MDATT index is proposed as a new index for the remote estimation of Chl content in plants with varying leaf surface structures [8]. Based on the Datt principle [16], this VI was modified by introducing the third band $\left(\lambda_{3}\right)$ according to Eq. (4). It aimed to compensate for high leaf surface (specular) reflectance and scattering from the mesophyll, which tend to alter reflectance across the whole VIS and NIR spectrum.

$$
\operatorname{MDATT}\left(R_{\lambda 1}, R_{\lambda 2}, R_{\lambda 3}\right)=\frac{R_{\lambda 3}-R_{\lambda 1}}{R_{\lambda 3}-R_{\lambda 2}} .
$$

PRI was originally developed [17] to estimate rapid changes in the epoxidation state of xanthophyll pigments, a major component of non-photochemical quenching. However, PRI has been increasingly used to detect photosynthetic activity at different scales from plant biochemistry to the canopy level. The MRESR index uses bands in the red edge and incorporates the correction of the leaf specular reflection. This VI is a robust measure of healthy green vegetation [18].

Simple ratio VIs: NR1, NR2 (Near infrared /Red), ZM (Zarco - Miller), G (Greenness), BG (Blue/Green) and VREI1 (Vogelmann Red Edge) were tested in several studies [10, 19], [9], [20-22], respectively, to evaluate leaf $\mathrm{Chl}$ content in different plant species and in different environmental conditions. VREI1 is sensitive to the combined effects of foliage Chl concentration, canopy leaf area, and water content. The VIs $1 / R_{700}$ and $1 / R_{550}-1 / R_{750}$ have recently received considerable attention and have been found to be well correlated with the leaf Chl content [23]. The green Chl and Red edge $\mathrm{Chl}$ indices ( $\mathrm{Chl}_{\text {green }}$ and $\mathrm{Chl}_{\text {red edge }}$ ) were proposed for a better prediction of Chl content [21].

The Chl Absorption Ratio Index (CARI) [24] measures the depth of Chl absorption at $670 \mathrm{~nm}$ relative to the green reflectance peak at $550 \mathrm{~nm}$ and the reflectance at $700 \mathrm{~nm}$ in order to reduce the effect of some non-photosynthetic materials. The modified CARI (MCARI) [25] is developed to further weaken the noise due to non-photosynthetic materials and is more sensitive to leaf $\mathrm{Chl}$ concentrations.

Due to the recent development of hyperspectral sensors, which acquire a quasi-continuous reflectance spectrum, new and more robust Chl detection VIs have been, and are being, developed. One example, proposed and tested in this study, is the Normalized Green Peak Index (NGPI), based on the changes in the SRC area in the green peak (500-670 nm). The triangular Vegetation Index (TVI) [26] is calculated as the area of a hypothetical triangle in the spectral space that connects the green peak, minimum Chl absorption, and the NIR shoulder.

\subsection{Data analysis}

In order to evaluate the potential of the selected VIs to discriminate the changes in leaf Chl content, statistical analyses were performed. A two-step procedure was adopted for the assessment of the presence and significance of the differences between VIs means of all pairs compared (the VIs of the control group with the VIs of every other group of the treated plants). First, to test whether differences exist between the VIs means, the null hypothesis Ho: $\mu 1=\mu 2=\mu 3=$ $\mu 4$ versus the alternative hypothesis $\mathrm{H} 1: \mu 1 \neq \mu 2 \neq \mu 3 \neq$ $\mu 4$, one-way analysis of variance (ANOVA) was used. Secondly, a multiple comparisons test using the TukeyKramer procedure was carried out in order to 
K. Velichkova, D. Krezhova, Hyperspectral vegetation indices..., Rad. Applic., 2018, 3, 3, 202-208

determine which pairs of VIs means have statistically significant differences. This test was applied because of the small sizes of the datasets, as well as with an approximately equal size $n_{i} \cong n_{j}$, where $n_{i}$ and $n_{j}$ are the numbers of data in $i$ and $j$ datasets, respectively.

Every two sets of VIs were compared by calculating the difference between their means $\Delta x$ and comparing it with the critical difference $\Delta x_{\mathrm{c}}$

$$
\Delta x_{c}=q_{c} \sqrt{\frac{M S_{W}}{2}\left(\frac{1}{n_{i}}-\frac{1}{n_{j}}\right)},
$$

where $M S_{W}$ is the mean square of error and $q_{\mathrm{c}}$ is the critical $q$-value taken from the Studentized Range $q$ table [27] for the confidence level $\alpha=0.05$ and the degree of freedom $d f=N-k$ ( $\mathrm{N}$ - the total number of data in all datasets, $\mathrm{k}$ - the number of datasets). If the difference $\Delta x_{\mathrm{ij}}$ between the means of the $i$ and $j$ sets is higher than $\Delta x_{\mathrm{c}}\left(\Delta x_{i j}>\Delta x_{c}\right)$, it is accepted that the mean values of the pairs compared are statistically different at a given significance level.

\section{RESULTS AND DISCUSSION}

The SRCs of the four investigated groups of pepper plants, measured one and two weeks after the infection with CMV, were analyzed at the spectral range of 450$850 \mathrm{~nm}$. The differences between the SRC of the control and treated plants were more expressed in the green (green peak, 500-670 nm) and NIR spectral ranges. The changes in leaf tissue caused an increase of the NIR reflectance. The decrease of Chl content, that is, Chl absorption, caused an increase of the reflectance in the green peak.

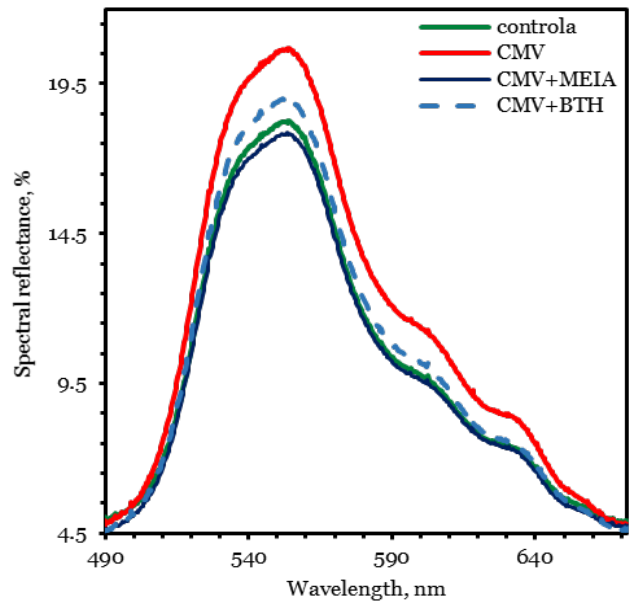

Figure 2. Averaged spectral reflectance characteristics of the control and treated pepper plants in the green peak measured one week after the inoculation with CMV

Averaged SRCs in the green peak, measured one week after the inoculation with CMV, are shown in Fig. 2. The differences between the SRC of the control plants and plants infected with CMV are most significant. For the combined treatments with two growth regulators and CMV (MEIA+CMV) and $(\mathrm{BTH}+\mathrm{CMV})$, the differences are less pronounced. The SRC values in the case of the (MEIA+CMV) treatment are closer to the control SRC, thus indicating a stronger effect of MEIA for the suppression of the viral infection compared to BTH.

Descriptive Excel statistics was used to verify the normal distribution of the VIs datasets for each group of plants. Normality was investigated using the Pearson and Shapiro-Wilk procedure. In the majority of cases (small exceptions) the distribution was normal, with a high coefficient of determination $\mathrm{R}^{2}$. As an example, Fig. 3 shows the box-plots of the datasets of MRESR VI calculated for the control and treated plants for two measurements (one and two weeks after the infection).

The ANOVA results show that the mean values of the indices for the control and treated plants are equal only for the NDVI and TVI. For all other indices, the ANOVA results show that there is at least one pair of groups whose means are different.

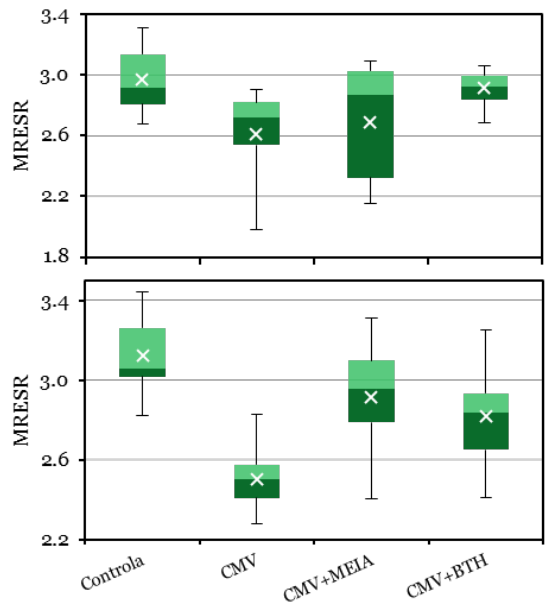

Figure 3. Box plots of the datasets of MRESR VI for the control and treated plants for the first (upper) and second (lower) measurements: median (the boundary between light and dark green boxes), mean value (white $x$ ), minimal and maximal values (lower and upper ends of the whisker, respectively), interquartile range containing $50 \%$ of values (both boxes)

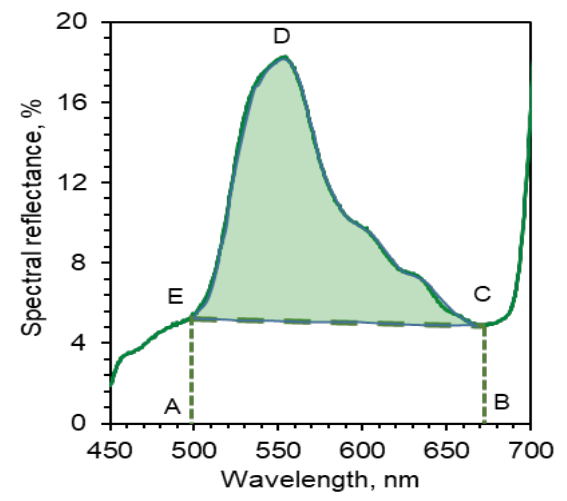

Figure 4. Normalized Green Peak Index (NGPI) 
K. Velichkova, D. Krezhova, Hyperspectral vegetation indices..., Rad. Applic., 2018, 3, 3, 202-208

Therefore, the Tukey-Kramer comparison procedure was applied to the VIs means for the investigated plants. The confidence level was $\alpha=0.05$, the degree of freedom was $d f=N-k=79-4=75$. The value of $q_{c}$ taken from the Studentized Range q table is: $q_{\mathrm{c}}=3.7162$.

The results obtained for the five selected VIs (as the representatives of each category of indices) are given in Table 2. $\Delta x_{i j}$ is the difference between the means of the $i$ and $j$ VI datasets, $\Delta x_{c}$ is the critical difference, and $\mathrm{p}$ is the level of significance.
The results show that the NDVI and TVI are insensitive to changes in Chl content. Best results show the MRESR, VREI1, and PI with statistically significant differences in investigated combinations 5, 4 and 4 , respectively. The position of the mean values of the MRESR for all groups (white $\mathrm{x}$ ) can be seen in Fig. 3 . The rest of the VIs were responsible for Chl variations but with less sensitivity.

The NGPI, proposed in this study, is the area of the leaf reflectance spectrum in the green peak, Fig. 4 , (CDE area).

Table 2. Difference between VIs means for pairs compared, critical difference, and p-values at level $\mathrm{p}=0.05$ for spectral data measured one week after the infection with CMV

\begin{tabular}{|c|c|c|c|c|c|}
\hline Type of VI & mNDVI & mDATT & SR1 & NGPI & MRESR \\
\hline Compared samples & $\Delta x_{\mathrm{ij}}$ & $\Delta x_{\mathrm{ij}}$ & $\Delta x_{\mathrm{ij}}$ & $\Delta x_{\mathrm{ij}}$ & $\Delta x_{\mathrm{c}}$ \\
\hline $\begin{array}{r}\text { Control - CMV } \\
\mathrm{p}\end{array}$ & $0.068_{* * *} 0.024$ & $0.007_{*}^{0.006}$ & $1.434_{* * *} 0.663$ & $0.056 \underset{* * *}{0.027}$ & $0.621_{* * *} 0.176$ \\
\hline $\begin{array}{c}\text { Control - CMV+MEIA } \\
\text { p }\end{array}$ & $\begin{array}{c}0.008 \underset{n s}{0.025} \\
\end{array}$ & $\begin{array}{l}0.001 \text { ns } \\
\text { ns }\end{array}$ & $\begin{array}{c}0.143 \underset{n s}{ } 0.679 \\
\end{array}$ & $\begin{array}{l}0.012 \text { ns } \\
\text { ns }\end{array}$ & $0.208_{* *} 0.181$ \\
\hline $\begin{array}{c}\text { Control - CMV+BTH } \\
\mathrm{p}\end{array}$ & $\begin{array}{l}0.018 \mathrm{~ns}^{0.025} \\
\end{array}$ & $\begin{array}{c}0.0060 .006 \\
n s\end{array}$ & $\begin{array}{c}0.195 \text { ns } \\
\text { ns }\end{array}$ & $0.037_{* *} 0.027$ & $0.303_{* * *} 0.179$ \\
\hline $\begin{array}{c}\mathrm{CMV}-\mathrm{CMV}+\mathrm{MEIA} \\
\mathrm{p}\end{array}$ & $0.060 \underset{* * *}{0.024}$ & $0.008_{* *} 0.006$ & $1.291_{* * *} 0.663$ & $0.044_{* * *} 0.027$ & $0.413_{* * *} 0.176$ \\
\hline $\begin{array}{c}\mathrm{CMV}-\mathrm{CMV}+\mathrm{BTH} \\
\mathrm{p}\end{array}$ & $0.050 \underset{* * *}{0.024}$ & 0.0020 .006 & $1.239 \underset{* * *}{0.654}$ & $\begin{array}{c}0.0190 .027 \\
n s^{*}\end{array}$ & $0.318 \underset{* * *}{0.174}$ \\
\hline $\begin{array}{c}\mathrm{CMV}+\mathrm{MEIA}-\mathrm{CMV}+\mathrm{BTH} \\
\mathrm{p}\end{array}$ & $\begin{array}{l}0.010{ }_{n s}^{0.025} \\
\end{array}$ & $0.007_{*} 0.006$ & $0.053 \underset{n s}{0.670}$ & $\begin{array}{c}0.025 \text { ns } \\
0.027 \\
\end{array}$ & $\begin{array}{c}0.095 \text { ns } \\
0.179 \\
\end{array}$ \\
\hline
\end{tabular}

ns (no statistical significance) - p >0.05; ${ }^{*}-\mathrm{p}<0.01 ;^{* *}-\mathrm{p}<0.005 ;{ }^{* * *}-\mathrm{p}<0.001$.

It is limited by the lowest reflectance in the green (point E) and red (point C) spectral ranges. This area was calculated for each of the four groups and normalized to the corresponding area $\mathrm{ABCDE}$, Eq. 5:

$$
1-\left(\lambda_{r}-\lambda_{g}\right)\left(R_{r}+R_{g}\right) /\left(2 \int_{\lambda_{g}}^{\lambda_{r}} R_{\lambda} \mathrm{d} \lambda\right)
$$

The NGPI did not have the highest correlation with the changes in the leaf Chl content in this dataset. Similar results gave $\mathrm{NR}_{1}$.

The averaged SRC of the control and treated pepper plants, measured two weeks after the inoculation, are shown in Fig. 5. The differences between the SRCs of the control and CMV infected plants remain most prominent.

The SRC values of the combined treatments (MEIA+CMV, BTH+CMV) are very close and lower than the control SRC which indicates an increase of the Chl content due to the stimulating action of the growth regulators.

The statistical analyses show that the number of statistically significant differences between the VIs means for most of the calculated VIs decreases by at least one. The result remains the same for the mNDVI, MDATT, ZM, and Chlred edge indices. For the NDVI (greenness index), two differences are significant, which is indicated by a certain change in the colour (greenness) of the leaves. For NR1, the number of significant differences increases with one. This was suggested in a previous work of the authors [10] on the detection of viral infection in potato plants and gave good results. For the NGPI, in the cases of Control$\mathrm{CMV}+\mathrm{MEIA}$ and Control-CMV+BTH, the differences were not significant.

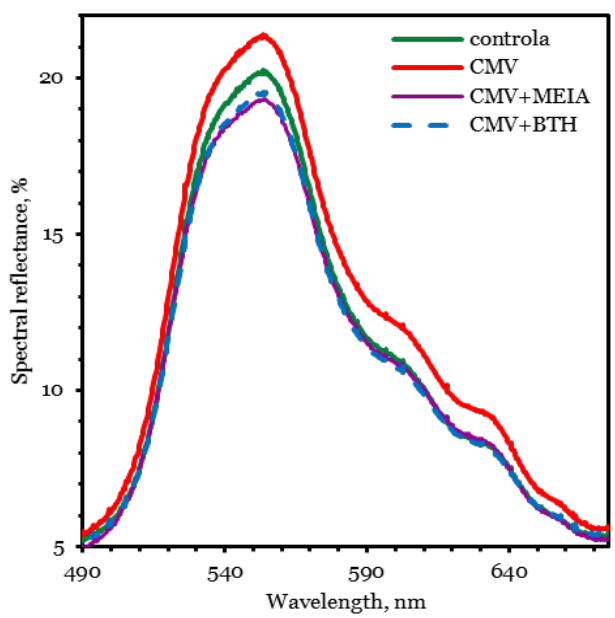

Figure 5. Averaged spectral reflectance characteristics of control and treated pepper plants in green peak two weeks after the inoculation with CMV

\section{CONCLUSION}

In this paper, nineteen hyperspectral vegetation indices from four categories were tested to explore their potentials in the Chl content estimation. A two- 
K. Velichkova, D. Krezhova, Hyperspectral vegetation indices..., Rad. Applic., 2018, 3, 3, 202-208

step statistical analysis (ANOVA and Tukey-Kramer test) was adopted for the assessment of the presence and significance of the differences between the VIs means. Three of the VIs (MRESR, VREI1, and PI) showed the best sensitivity. The rest of the VIs were responsible for Chl variations but with less sensitivity. One new VI (NGPI) was proposed and tested in this study based on the changes in the SRC area in the green peak (500-670 $\mathrm{nm})$. The statistical analysis showed an adequate response of the NGPI to the quantity changes in the SRC due to Chl content variations. The proposed approach in this study, based on the analyses of the quantitative relationships between the changes in the Chl content and various narrow-band Vis, has a great practical application for a rapid and non-destructive assessment of Chl content and in particular for studying biophysical and physiological properties of plants under stress.

\section{REFERENCES}

1. F. Fiorani, U. Schurr, "Future Scenarios for Plant Phenotyping," Annu. Rev. Plant. Biol., vol. 64, pp. 267 - 291, Apr. 2013.

DOI: 10.1146/annurev-arplant-050312-120137 PMid: 23451789

2. E. Levizou, P. Drilias, G. K. Psaras, Y. Manetas, "Nondestructive assessment of leaf chemistry and physiology through spectral reflectance measurements may be misleading when changes in trichome density co-occur," New Phytol., vol. 165, no. 2, pp. $463-472$, Feb. 2005.

DOI: $10.1111 /$ j.1469-8137.2004.01250.x

PMid: 15720657

3. D. A. Sims, J. A. Gamon, "Relationships between leaf pigment content and spectral reflectance across a wide range of species, leaf structures and developmental stages," Remote Sens. Environ., vol. 81, no. 2-3, pp. $337-354$, Aug. 2002. DOI: 10.1016/Soo34-4257(02)00010-X

4. A. P. Leone, N. Leone, S. Rampone, "An application of VIS-NIR reflectance spectroscopy and artificial neural networks to the prediction of soil organic carbon content in Southern Italy," Fresen. Environ. Bull., vol. 22, no. 4b, pp. 1225 - 1229, Apr. 2013.

Retrieved from:

http://xoomer.virgilio.it/rampon/visnir20132.pdf; Retrieved on: Feb. 12, 2018

5. C. Zhang, I. Filella, M. F. Garbulsky, J. Peñuelas, "Affecting factors and recent improvements of the photochemical reflectance index (PRI) for remotely sensing foliar, canopy and ecosystemic radiation-use efficiencies," Remote Sens., vol. 8, no. 9, pp. 677 - 709, Sep. 2016. DOI: $10.3390 / \mathrm{rs} 8090677$

6. Y.C. Tian et al., "Assessing newly developed and published vegetation indices for estimating rice leaf nitrogen concentration with ground- and space- based hyperspectral reflectance," Field Crops Res., vol. 120, no. 2, pp. 299 - 310, Jan. 2011. DOI: $10.1016 /$ j.fer.2010.11.002

7. A. J. S. Neto, D. de Carvalho Lopes, J. C. F. Borges Júnior, "Assessment of Photosynthetic Pigment and Water Contents in Intact Sunflower Plants from Spectral Indices," Agriculture, vol. 7, no. 2, pp. 8 - 16, Feb. 2017.

DOI: 10.3390/agriculture7020008

8. S. Lu et al., "Comparing vegetation indices for remote chlorophyll measurement of white poplar and Chinese elm leaves with different adaxial and abaxial surfaces," J. Exp. Bot., vol. 66, no. 18, pp. 5625 - 5637, Sep. 2015. DOI: $10.1093 / \mathrm{jxb} / \mathrm{erv} 270$

PMid: 26034132

PMCid: PMC 4585420

9. P. J. Zarco-Tejada et al., "A PRI-based water stress index combining structural and chlorophyll effects: Assessment using diurnal narrow-band airborne imagery and the CWSI thermal index," Remote Sens. Environ., vol. 138, pp. 38 - 50, Nov. 2013. DOI: $10.1016 /$ j.rse.2013.07.024

10. D. Krezhova, S. Maneva, N. Petrov, K. Velichkova, „Remote sensing of the influence of the biotic stress on plant biophysical variables," Radiation \& Applications, vol. 2, no. 1, pp. 46 - 52, Apr. 2017. DOI: $10.21175 /$ RadJ.2017.01.010

11. E. R. Hunt, P. C. Doraiswamy, J. E. McMurtrey, C. S. T. Daughtry, E. M. Perry, "A Visible Band Index for Remote Sensing Leaf Chlorophyll Content at the Canopy Scale," Int. J. Appl. Earth Obs. Geoinf., vol. 21, pp. 103 - 112, Apr. 2013. DOI: $10.1016 /$ j.jag.2012.07.020

12. N. Petrov, M. Stoyanova, M. Valkova, "Antiviral activity of plant extract from Tanacetum vulgare against Cucumber Mosaic Virus and Potato Virus Y," J. BioSci. Biotechnol, vol. 5, no. 2, pp. 189 - 194, Jul. 2016.

Retrieved from:

http://www.jbb.uniplovdiv.bg/documents/27807/1703628/2016-5-2-189194.pdf;

Retrieved on: Mar. 12, 2018

13. J. Rouse, R. Haas, J. Schell, D. Deering, Monitoring Vegetation Systems in the Great Plains with ERTS, Rep. PAPER-A2O, NASA, Washington (DC), USA, 1973. Retrieved from:

https://ntrs.nasa.gov/search.jsp?R=19740022614; Retrieved on: Mar. 12, 2018

14. S. $\mathrm{Lu}$ et al., "A robust vegetation index for remotely assessing chlorophyll content of dorsiventral leaves across several species in different seasons," Plant Methods, vol. 14, no. 15, pp. 2 - 15, Feb. 2018.

DOI: $10.1186 / \mathrm{s} 13007-018-0281-\mathrm{z}$

PMid: 29449875 PMCid: PMC5812224

15. C. Jurgens, "The modified normalized difference vegetation index (mNDVI) a new index to determine frost damages in agriculture based on Landsat TM data," Int. J. Remote Sens., vol. 18, no. 17, pp. 3583 - 3594, Nov. 1997.

DOI: $10.1080 / 014311697216810$

16. C. B. Datt, "A New Reflectance Index for Remote Sensing of Chlorophyll Content in Higher Plants: Tests Using Eucalyptus Leaves," J. Plant Physiol., vol. 154, no. 1 , pp. $30-36$, Jan. 1999. DOI: 10.1016/So176-1617(99)80314-9

17. J.A. Gamon, J. Peñuelas, C. B. Field, "A narrowwaveband spectral index that tracks diurnal changes in photosynthetic efficiency," Remote Sens. Environ., vol. 41, no. 1, pp. 35 - 44, Jul. 1992. DOI: 10.1016/0034-4257(92)90059-S

18. M. F. Garbulsky, J. Peñuelas, J.A. Gamon, Y. Inoue, I. Filella, "The photochemical reflectance index (PRI) and the remote sensing of leaf, canopy and ecosystem radiation use efficiencies: a review and meta-analysis," Remote Sens. Environ., vol. 115, no. 2, pp. 281 - 297 Feb. 2011. DOI: 10.1016/j.rse.2010.08.023

19. G. A. Blackburn, "Spectral indices for estimating photosynthetic pigment concentrations: A test using senescent tree leaves," Intern. Remote Sens., vol. 19, no. 4, pp. $657-675,1998$. DOI: $10.1080 / 014311698215919$ 
K. Velichkova, D. Krezhova, Hyperspectral vegetation indices..., Rad. Applic., 2018, 3, 3, 202-208

20. J. L. Rougean, F. M. Breon, "Estimating PAR absorbed by vegetation from bidirectional reflectance measurements," Remote Sens. Environ., vol. 51, no. 3, pp. 375 - 384, Mar. 1995. DOI: 10.1016/0034-4257(94)00114-3

21. A. A Gitelson, Y. Gritz, M. N. Merzlyak, "Relationships between leaf chlorophyll content and spectral reflectance and algorithms for nondestructive chlorophyll assessment in higher plant leaves," J. Plant Physiol., vol. 16o, no. 3, pp. 271 - 282, Mar. 2003. DOI: $10.1078 / 0176-1617-00887$

22. J. Vogelmann, B. Rock, D. Moss. "Red Edge Spectral Measurements from Sugar Maple Leaves," Intern. J. Remote Sensing, vol. 14, no. 8, pp. 1563-1575, 1993. DOI: $10.1080 / 01431169308953986$

23. A. A. Gitelson, A. Viña, V. Ciganda, D. C. Rundquist, T. J. Arkebauer, "Remote estimation of canopy chlorophyll content in crops," Geophys. Res. Lett., vol. 32, no. 8, Lo8403, Apr. 2005 DOI: $10.1029 / 2005$ GLo22688

24. M.S. Kim, "The use of narrow spectral bands for improving remote sensing estimation of fractionally absorbed photosynthetically active radiation (fAPAR)," M.Sc. dissertation, University of Maryland, Dept. of Geography, College Park (MD), USA, 1994.

25. S. T. Daughtry, C. L. Walthall, M. S. Kim, E. B. de Colstoun, J. E. McMurtrey III, "Estimating corn leaf chlorophyll concentration from leaf and canopy reflectance," Remote Sens. Environ., vol. 74, no. 2, pp. $229-239$, Nov. 2000.

DOI: 10.1016/So034-4257(00)00113-9

26. N. Broge, E. Leblanc, "Comparing prediction power and stability of broadband and hyperspectral vegetation indices for estimation of green leaf area and canopy chlorophyll density," Remote Sens. Environ., vol. 76, no. 2, pp. 156 - 172, May 2000.

27. Ch. Zaiontz, Real Statistics Using Excel: Studentized Range $q$ Table, Real Statistics.

Retrieved from:

http://www.real-statistics.com/statistics-

tables/studentized-range-q-table/;

Retrieved on: Mar. 12, 2018 